\title{
Neither Rupture Nor Continuity: Memorializing the Dawn of the Space Age in Contemporary Russian Cinematography
}

\author{
Natalija Majsova
}

Around half a century after the launch of the Sputnik in 1957 and the first feats of space programmes, and a couple of decades into the so-called commercialization of outer space, scholars in the humanities and social sciences seem to be returning to the question: 'Wherein lies the significance of the space age in the first place?', a question which may hardly be addressed properly using a single theory or methodological toolbox due to its complexity. At first glance, there appears to be a general consensus on the global, if not universal, significance of the event. The dawn of the space age and its resonant events, such as the launch of the Sputnik, Gagarin's flight or the Moon-landing, are often seen as great milestones in scientific and technological progress: a symbol of humanity's unity in its terrestrial origin, a signpost signaling the humility and loneliness of life on Earth in the vast cosmic space. On the other hand, these memory narratives of the dawn of the space age mostly remain constrained to national or regional frameworks. ${ }^{1}$ Nevertheless, the general consensus persists that the aforementioned achievements are of global and transcultural relevance.

The aim of this text is to add to existent debates by exploring memory narrative reception through two particular cinematic (re)appropriations of the

1 For instance, a quick overview of existent scholarly literature shows that American space policy has, from its inception, predominantly been focused on the political, military and societal aspects of spaceflight. European space policy, on the other hand, has positioned itself in alignment with the economic and scientific benefits of space technologies, while the Russian space program has thus far devoted most attention to the cultural dimension of space exploration. Furthermore, memorialization media, such as popular globally 'iconic' imagery of/from outer space mostly involve images taken by NASA [National Aeronautis and Space Administration] and ESA [European Space Agency], and not by other space agencies; sites of memory and media of memory narrative construction, such as space history and space technologies museums around the world tend to favor local national achievements, rather than focus on the space age as a global achievement.

(C) NATALIJA MAJSOVA, 2017 | DOI 10.1163/9789004352353_010

This is an open access chapter distributed under the terms of the CC-BY-NC License. 
narrative of the dawn of the space age. The text will examine how an audiovisual medium, such as cinema, can productively contribute to existent and persistent memory practices that mark our understanding of humanity's first tangible encounters with outer space in the late 1950 s and early 1960 s. $^{2}$ The analysis shall be limited to a particular case study: contemporary Russian cinematic production on the advent of the space age. However, it will be argued in the conclusion that such local manifestations have multifaceted significance for a potential transcultural European narrative on the issue.

Following a brief contextualization of the place of the dawn of the space age in contemporary cinema, particularly Russian cinema, the text will examine in detail two cases in point. Two case studies of contemporary Russian cinema (Kosmos kak predchuvstviye [Dreaming of Space] (dir. Alexei Uchitel', 2005) and Pervye na Lune [First on the Moon] (dir. Alexei Fedorchenko, 2004) will be used to examine the following pertinent issues. Firstly, are cinematic accounts focusing on the beginning of the space age mere reiterations of mainstream narratives about the history of space flight or do they call for reinterpretations of prevailing narratives on the significance of spaceflight? Secondly, are cinematic accounts focusing on the beginning of the space age nationally bound, i.e. do they reflect nationally specific narratives, attitudes, cinematographic canons and reference frameworks or do they appropriate and (re)interpret these narratives, attitudes, canons and reference framework in order to highlight issues of transnational significance? If the latter is true, what are these underlying issues and how do contemporary cinematic productions approach them? In addressing these questions, the text will argue that (neo)formalist film analysis - i.e. analysis particularly attentive to cinematic form ${ }^{3}$ - plays an important role in highlighting cinema's significance as a reception practice, and should supplement audience film reception analyses.

2 It has been noted by Erll and Nünning that film 'exists in a relationship to contemporary discourses of memory and illustrates functions, processes, and problems of memory in the medium of fiction through aesthetic forms' (Astrid Erll and Ansgar Nünning, "Concepts and Methods for the Study of Literature and/as Cultural Memory," Literature and Memory. Theoretical Paradigms. Genres. Functions (2006): 11-28.). In this chapter, I would like to take this argument a little further in order to suggest that cinematic fictional construction of memory narratives is also a level of reception of these narratives: cinematic adaptation may be seen as a level of memory narrative reception. Quite often, cinema intentionally plays around with officially approved memory narratives, in order to construct new ones.

3 Cf. Kristin Thompson, Breaking the glass armor: neoformalist film analysis (Princeton: Princeton University Press, 1988). 


\section{A Note on Method: Films, Memory, and Reception}

Film analysis is a tricky issue, because it involves 'translating' the cinematic audio-visual medium into text, i.e. sequences of written words. This process of interpretation is highly subjective, and reflects numerous factors, which shape the interpreter's commentary and reception. A film critic will often focus more on different aspects of a given film than a lay spectator, who is not consciously attentive to cinematic form and whose film-viewing practices are informed and shaped by a given context and daily routine. However, cinematic remediations of cultural narratives emerge precisely at this intersection of a thousand plateaus of reception practices. This chapter explores the implications of looking at different reception plateaus side by side, in order to explore the different facets of the cinematic medium that take part in memory reception processes.

While narrative analysis may be the most obvious way of looking at how films participate in cultural memory production and remediate, i.e. transpose into a different medium, re-tell, re-shape, in order to shift emphases and meanings, recent studies increasingly point to the importance of assessing other features of the cinematic medium: '/b/y communicating memories and counter-memories as well as the loss of memories the films not only share the recollections of their protagonists, and their ways of evoking certain events of their past, with the audience; they also use the cinematic apparatus and visual language to (re)present and (re)shape our understanding of memoryconstitution.' ${ }^{4}$ Films are therefore more than just motion pictures that illustrate novels and short stories. Cinematic form (lighting, mise-en-scène, music, colour, timespace construction) conveys a lot of non-verbal information about a film. Sometimes, this information is difficult to verbalize, and is only tacitly reflected in (particularly non-scholarly) film reviews: a reviewer may note that a film is 'grim' without explaining how this grimness is constructed formally. Such observations are precious comments on how films participate in memory processes: they point to divergences between narrative and form, and to ambiguities, which are key to the power of some memories; sometimes, an impression is created precisely because a certain narrative is insufficient for explaining a certain 'overall ambience' of an event. Or, in other words: 'film's impact lies less in its empirical qualities than in its powerful capacity

4 Verena Susanna Nungesser, "I Forgot to Remember (to Forget): Personal Memories in Memento (2000) and Eternal Sunshine of the Spotless Mind (2004)", in Media and Cultural Memory, ed. Astrid Erll and Ansgar Nünning (Berlin, New York: Walter de Gruyter, 2009), $31-48$. 
to influence public consciousness, mould collective memory and retrieve suppressed or marginalised histories. ${ }^{5}$ This 'powerful capacity' of film lies in its always-incomplete coalescence with verbalized film reviews.

Therefore, while considering the cinematic medium as a memory practice, and looking at how it contributes to memory reception, this text relies on several methodological remarks. The starting premise is that 'rather than assuming that the world on film should somehow adhere to the standards of written history, why not see if it has created its own standards over the last century, techniques for turning the past into history which are appropriate to the possibilities and practices of the medium, including those of drama, which is the standard way in which film tells its stories, past or present.' ${ }^{6}$ This premise allows us to consider the films themselves as memory practices and memory reception tools at the same time. In relation to memory, films are not only remediations of certain historical narratives, but also, at the same time, receptions of certain narratives: films are interpretations of narratives, constructed and approved by individual film auteurs of governance bodies that had commissioned the production of a film or both. Since this text looks closely at two auteur films, the former dimension will be considered as dominant over the latter. Therefore, cinematic interplay in memory reception processes is a 'double-bind': spectator reception is always reception of a certain reception, particularly in a case like ours, when fiction cinema is examined. Fiction cinema does not require a spectator to look for facts or coherence; it typically evokes diverse responses, only some of which note its possible contextual references.

In this text, lay spectators' reception will be juxtaposed with neoformalist analysis, which will provide insight into two issues: firstly, into the formal, aesthetic and stylistic reception of the narrative of the dawn of the space age, given by the two films, and, secondly, into the convergences and divergences between the official (verbal) narrative of the dawn of the space age and its significance, the aesthetic reception of these accounts, provided by two auteur film directors, and the reception of these cinematic accounts by lay audiences. This triple-loop will allow us to trace the subtle transformations that memory processes undergo in various phases of remediation and reception.

5 Jennie M. Carlsten and Fearghal McGarry, "Introduction", in Film, History and Memory, ed. Jennie M. Carlsten and Fearghal McGarry (London: Palgrave Macmillan, 2015), 1.

6 Jennie M. Carlsten and Fearghal McGarry, "Introduction", in Film, History and Memory, ed. Jennie M. Carlsten and Fearghal McGarry (London: Palgrave Macmillan, 2015), 6. 


\section{Memorializing the Dawn of the Space Age in the 21st Century}

Current debates on the significance of man's first indirect (satellites and spacecraft carrying plants and animals) and direct (manned spaceflight) ventures into the upper parts of Earth's atmosphere and beyond tend to focus on several key dimensions. One of them is narratives that shape our understanding of the socio-political and cultural context of these unprecedented events. These narratives typically contextualize the groundbreaking nature of the dawn of the space age within national and international frameworks, more or less narrow in scope. Narrower frameworks scale the significance of humanity's ventures into outer space down to sociopolitical, cultural and science and technological histories of spaceflight, while analyses aiming at broader horizons focus on frameworks of international and global politics. ${ }^{7}$ While such rationalist narratives that tend to focus on the political, military and economic Cold war race for primacy in outer space, as well as those that highlight man's unconditional faith in scientific progress, persist, ${ }^{8}$ they cannot fully account for the equally persistent fascination enveloping the globally resonant space-related events of the late 1950 and early 1960 .

Echoing this point, Shukaitis ${ }^{9}$ convincingly argues that the rationale guiding investments into outer space exploration (as well as space conquest and space tourism) of the 2oth and early 21st centuries can essentially be interpreted through two sequential matrices. The first, relevant for the period prior to the end of the Cold war, is a political matrix, i.e. the framework of the race for space, where dominion of the heavenly realm was seen as an analogy to political, technological, and therefore military supremacy on Earth. The second, foregrounded after the end of the Cold war and a short period of the prevalence of environmentalist arguments against investments in costly space programs, is a matrix following the logic of capitalist expansion. Here, outer space is conceptualized as a plausible solution, a welcome aid for managing structural crises of capitalism, which have to be addressed by new investments into ever

7 For a good overview, consult Roger D. Launius and Howard E. McCurdy, Imagining Space: Achievements, Predictions, Possibilities 1950-2050 (San Francisco, CA: Chronicle Books, 2005).

8 Here, I am referring to works such as Asif A. Siddiqi, The Red Rocket's Glare: Spaceflight and the Soviet Imagination, 1857-1957 (Cambridge: Cambridge University Press, 2010). and Eva Maurer, Julia Richers, Monica Ruthers and Carmen Scheide, eds., Soviet Space Culture: Cosmic Enthusiasm in Socialist Societies (London: Palgrave MacMillan, 2011) which highlight the cultural context of space enthusiasm in the Soviet Union.

9 Shukaitis, Stevphen. "Space is the (non)place: Martians, Marxists, and the outer space of the radical imagination." The Sociological Review 57 (2009): 98-113. 
further horizons. ${ }^{10}$ In both cases, outer space essentially functions as a semifictional (i.e. unknowable) horizon upon which the logic of Earthly affairs (politics, economics) is simply extrapolated with very few - if any - adjustments. Shukaitis argues that these approaches evidently ignore the unknowability of outer space, and its capacity to function as an 'imaginal machine'll expanding our horizons of thought. There appears to be little room for fascination with the unknown in the domains and language used by politics and economics.

Indeed, if anywhere, the issue of the fascination of outer space, the unknown and inherently unknowable cosmos, is addressed in sociological and media studies analyses of representations of outer space, the dawn of the space age and its future in cultural production. Starting off with this very presumption about the possibility of conceptualizing outer space and humanity's interaction with it in a different way, analyses such as Llinares'12 examination of the figure of the astronaut in popular culture and Marie Lathers' analysis of women in American science fiction, ${ }^{13}$ Rogatchevski's ${ }^{14}$ exploration of Soviet and Russian outer space cinematic production, among others, reinterpret media texts in order to demonstrate that, by and large, they fail to alter narratives on the dawn of the space age and its significance, generated by other disciplines. The first cases of manned space flight thereby remain interpreted as achievements, entirely reducible to their immediate, contextual conditions of possibility. Although several authors, such as McCurdy, Harrison, Geppert and Dick ${ }^{15}$ do acknowledge that 'imagination', a concept which here refers to

10 Shukaitis, "Space is the Non-Place", 110.

11 More precisely: 'Outer space, far from being a pure space that is always available for recomposing imaginal machines, also connects areas of political thought that veer off in strange and bizarre directions, showing that, as Deleuze and Guattari would concur in their more sober moments, absolute deterritorialization can easily end in death, insanity, or absurdity', Shukaitis, "Space is the Non-Place", 100.

12 Dario Llinares, The astronaut: Cultural mythology and idealised masculinity (Cambridge: Cambridge Scholars Publishing, 2011).

13 Marie Lathers, Space Oddities: Women and Outer Space in Popular Culture 1960-200o (New York: Continuum Books, 2010).

14 Andrei Rogatchevski, "Space Exploration in Russian and Western Popular Culture: Wishful Thinking, Conspiracy Theories and Other Related Issues." In Soviet Space Culture: Cosmic Enthusiasm in Socialist Societies, ed. Eva Maurer, Julia Richers, Monica Ruthers, Carmen Scheide (London: Palgrave Macmillan, 2011), 211-265.

15 Cf. Stephen J. Dick, "Space, Time and Aliens: The Role of Imagination in Outer Space," In Imagining Outer Space: European Astroculture in the 2oth Century, ed. Alexander C.T. Geppert, 27-45. Basinstoke, New York: Palgrave MacMillan, 2012; Alexander C.T. Geppert, ed., Imagining Outer Space: European Astroculture in the Twentieth Century (Basingstoke, New York: Palgrave Macmillan, 2012); Howard E. McCurdy, Space and the American 
the free play of human mental capacities, is an important dimension of these conditions, and proceed to link 'imagination' to the realm of aesthetics, there appear to be no analyses of contemporary artistic reflections on the narrative of the dawn of the space age that begin with, and concentrate primarily on, a formalist analysis of their aesthetics. However, as I will attempt to argue in this contribution, aesthetics is an important dimension of memory reception and reinterpretation, and should be given more emphasis in debates on cultural production of memory narratives than is currently the case.

\section{Looking for a Transcultural Narrative on the Memory of the Dawn of the Space Age through Cinematic Aesthetics}

Casting the intriguing sociopolitical, economic and technological context aside for a moment, the dawn of the space age may also be regarded as a philosophically intriguing point in history; a point of recurrence of an exceptionally old question about the place of humankind in the world at large, i.e. in the cosmos, rather than in a certain state, region or even on a certain planet. Philosophical and artistic reactions to the advent of the space age often focus on this very aspect of the event in question, testifying to its transculturality and universality ${ }^{16}$ This issue is particularly prominent in the works of Russian cubofuturists and suprematists of the early 2oth century, as well as in the works of a wide array of 2oth century philosophers of differing provenance and theoretical backgrounds (e.g. Hans Blumenberg, Günther Anders, Hanna Arendt and Jacques Lacan); ; it has also been explored performatively in science fiction literature. Today, over half of a century after humanity's first direct encounters with outer space, the question of the relevance of these encounters and their legacy for redefining humanity's conceptualizations of its place in the world, and even of life as such, is no less relevant, as demonstrated by projects at the intersection of art and science, such as Vermeulen's Seeker ${ }^{18}$ inter alia. In these projects,

Imagination. Baltimore (MA: JHU Press, 1994); Albert A. Harrison, Spacefaring: The Human Dimension (Berkeley, CA: University of California Press, 2002).

16 Cf. Christine Poggi, Inventing futurism: The Art and Politics of Artificial Optimism (Princeton, New Jersey: Princeton University Press, 2009).

17 For more on contemporary philosophical accounts on the implications of the dawn of the space age, see Natalija Majsova, "The Metaphor of the Dawn of the Space Age in Contemporary Social Sciences and Humanities," Družboslovne razprave 31 (2015): 13-30.

18 'Seeker' is artist Angelo Vermeulen's worldwide community art project creating starship prototypes, initiated in 2009. Accessed at http://www.angelovermeulen .net/?portfolio=seeker, 12 May 2016. 
aesthetics functions as a propulsive force in the domain of artistic practice. Aesthetics has the potential to drive and shift our horizons of thought, the coordinates framing our understanding of the world around us and its priorities. However, contemporary artistic production, practices and experience do not only explore the prospects of space exploration, but also address the legacy of the dawn of the space age. It is argued in this chapter that analyses of such artistic productions also need to be examined through the lens of aesthetics, in order to cast a new light on the memory narratives on the dawn of space exploration prevalent in western literature today.

Russian cinematic production is a telling case in point, and may be considered underresearched due to a lack of analyses focusing on aesthetics. Indeed, Russian cinema on outer space hinges on the tradition of Soviet cinematic production dealing with outer space, comprising genres such as scientific fantasy, ${ }^{19}$ children's scientific fantasy, popular-scientific fiction cinema, biographical dramas focusing on the lives and aspirations of prominent figures in the Soviet history of spaceflight, and even cyberpunk, as well as the commercial and dystopian science fiction which appeared during the perestroika period. Space related cinematic production, particularly fiction, of the Soviet era up until the perestroika period is of special significance, as it is positioned directly at the nexus of ideology, framing Soviet cinematic production, ${ }^{20}$ and aesthetics, so evidently dominant in films such as Tarkovsky's Solyaris [Solaris] (1972).

Comparatively, contemporary (post-2001) Russian cinematography has far greater capacities for exploring outer space and the legacy of the dawn of the space age in terms of aesthetics as it is not governed by a single aesthetic canon. Conversely, post-2001 Russian cinema on outer space is a productive medium for exploring memory practices related to the dawn of the space age, and is of analytical interest for different reasons than Soviet space related production, marked by the aforementioned tension between aesthetics and the socialist realist canon on the one hand, and an enthusiasm about space-related films, stemming from the fact that Soviet outer space supremacy was portrayed as

\footnotetext{
19 For the history of the term 'scientific fantasy' and its relation to science fiction, see Darko Suvin, Russian Science Fiction 1956-1974 (Elizabethtown, NY: Dragon Press, 1976).

20 Certainly, communist ideology and the canon of socialist realism greatly influenced outer space related fiction in other media, such as literature; however, if independent cinematic production capacities were virtually non-existent, writers and poets still had the option of resorting to, for example, samizdat. Cf. Matthias Schwartz, "Die Besiedelung der Zukunft. Zur Neubegründung der sowjetischen Science Fiction nach dem ersten Sputnikflug 1957," In Bluescreen. Visionen, Träume, Albträume und Reflexionen des Phantastischen und Utopischen, ed. Walter Delabar and Frauke Schlieckau (Bielefeld: Magazin für Literatur und Politik, Heft 43-44, 2010), 105-122.; Suvin, Russian Science Fiction 1956-1974.
} 
a building block of Soviet (supra)national identity, on the other. After the fall of the Soviet Union, which produced over 40 outer space related feature films, there were virtually no films on this topic produced in Russia until $2004 \cdot{ }^{21} \mathrm{~A}$ renewed rise of interest for outer-space-related feature film production of various genres in Russia observed after 2001 is likely to be a combination of various factors, such as a renewed political interest in the achievements of the Soviet era and its nation-building myths, increased resources for film production after the turbulent 199os, as well as an updated marketing and branding strategy of the Russian space agency, Roscosmos, which established its own television studio, Tvroscosmos, in 2006, which performs many outer-space-achievements promotion activities etc.

While it is impossible to give a complete explanation for why the rate of production of outer space related feature films has returned to that characteristic of Soviet production, amounting to more than one space related fiction feature film per annum; it is possible to give an overview of the overarching features of this production. Tvroscosmos, as well as certain other forums, insists on listing all outer space related fiction feature cinematography in one category: 'on outer space', rather than categorizing the films into more established genres such as melodrama, scientific fantasy, comedy, children's comedy etc. The archive of this category of films currently comprises ten feature films (1994-2013, with only one film produced in 1994, i.e. Chetvyortaya planeta [The Fourth Planet] (dir. Dmitry Astrakhan), including three science fiction films, two art cinema dramas, one children's science fiction film, a mockumentary, two biographical dramas and one historical drama. ${ }^{22}$ The two art cinema films (Bumazhnyi soldat [Paper soldier], 2008, dir. Alexey German Jr.) and Kosmos kak predchuvstviye [Dreaming of Space] dir. Alexey Uchitel', 2005) and the mockumentary (Pervye na Lune [First on the Moon, dir. Alexey Fedorchenko, 2004]) have thus far received the most academic and critical attention. However, none of these existent reviews and analyses seem to focus on their aesthetic impulse: reviewers focus on the fictional worlds constructed by the films, their driving dynamics and their inherent preoccupations, preferring rather to foreground their historical references (or lack of them) and overarching message (or lack thereof). The following analysis attempts to do the very contrary in order to bring out the productive, re-interpretative momentum in cinematic memorializations of an event, i.e. the dawn of the space age. This is done in order to demonstrate that, firstly, the transcultural reverberations of this event as a universally significant transformation of our reality persist, and should be ac-

21 Cf. the archives of Tvroscosmos, available at the Tvroscosmos website.

22 All information on Tvroscosmos and its archives is available on the organization's website. 
corded more emphasis if a transcultural narrative of the dawn of the space age is to emerge, and, secondly, that formalist analysis of aesthetics should be incorporated into memory narrative reception analyses, dealing with the visual arts and complementing analyses of audience reception of these films.

\section{Russian Cinematic Memories of the Dawn of the Space Age: Two Case Studies}

For the purposes of this text, case studies of two of the fiction films belonging to the category 'on outer space' delineated above shall be presented: an art film directed by Alexey Uchitel', Kosmos kak predchuvstviye [Dreaming of Space] (2005), and a mockumentary directed by Alexey Fedorchenko, Pervye na Lune [First on the Moon] (2004). Both films belong to the popular Russian cultural production on outer space, a significant percentage of which is concerned with memories of the glorious days of the Soviet space program, rather than with its future, or science fiction. ${ }^{23}$ These films are no exception. Kosmos kak predchuvstviye [Dreaming of Space] is a melancholic account about the lives of two men and two women, and their relations in the Russian North, just after the launch of the Sputnik, and before Gagarin's flight. Pervye na Lune [First on the Moon] is a mockumentary about the Soviet space program in the 193os, when a manned spacecraft was allegedly launched to the Moon, and crashed in Chile. Both films were produced with the support of the Russian Ministry of Culture, and had rather generous budgets (USD 2,000,00o in the case of Kosmos kakpredchuvstviye [Dreaming of Space] and USD 1,000,00o in the case of Pervye na Lune [First on the Moon]). Pervye na Lune [First on the Moon] received an ironic award: it was announced to be the best documentary of the year at the film festival in Venice in 2005; it also reaped the awards of the best debut and best film according to film critics at the Kinotavr festival in 2005, as well as best feature film in Zagreb in 2005. Kosmos kak predchuvstviye [Dreaming of Space] reaped numerous awards in Russia, e.g. best feature film at the Moscow International film festival in 2005, best operator and best male actor at the Nika film festival in 2006, as well as best director and best script at the 2006 Zolotoi Oryol Film festival. ${ }^{24}$

Both films were received ambiguously by the home and foreign audiences. As it will be demonstrated in the following paragraphs, despite positive expert

23 Cf. Rogatchevski, "Space Exploration in Russian and Western Popular Culture," 212-216.

24 Information on the production and reception context of the films was acquired on the films' websites and internet movie databases, in this case Kinopoisk.ru and IMDB. 
reception, online layman reviews accessible on international Russian and English-language cinema portals (Kinokultura, Kinopoisk.ru, Ruskino.ru, Kinoteatr.ru, $I M D B$ ), which frame many potential spectators' first impressions of the film and influence their decisions on whether they will proceed to watch the films or not, often fail to recognize a direct relation between these cinematic texts and the topic they claim to be addressing: memories of the dawn of the space age. In the following analysis, it will be attempted to re-establish this connection: the two films will be analyzed as reinterpretations of narratives on the key factors of the global and universal significance of the dawn of the space age.

\section{Kosmos kak predchuvstviye [Dreaming of Space]}

At the beginning of our analysis of the first of the two films in question, let us make a brief digression to the translation of the title of the film into English, in order to exemplify the aforementioned entanglements between text and its production and reception context. Had the title been translated with greater precision, Kosmos kak predchuvstviye [Dreaming of Space] would be known as 'Space as a Premonition', inaugurating the film with a slightly different connotation. Nevertheless, most reviews of the film tend to disregard the title and focus on everything but outer space. As pointed out by a reviewer on IMDB who clearly has a precise opinion about contemporary Russian cinema and its quality: ${ }^{25}$

... What is this movie really about? How bad it was to live in UssR? Or how American music was supposedly better than Russian? And what does all of that have to do with space travel? My take on this: even though made in Russia, this movie was made for the West. Why? Well, first, the story line is primitive and characters are not developed (anticipating viewers ADD and taste). A Western viewer, if he ever goes to see a foreign, or, even worse, Russian movie, expects simple things: grotesque scenes from Russian life, plump Russian girls, drunk Russian guys, 'superior'

25 The Iмдв review was accessed at http://www.imdb.com/title/tto464665/reviews?ref_=tt_ urv, 3 May 2015. It is one of five reviews on the film available at the website. All five reviews conclude that the film is, in one way or another, a reconstruction of the depicted era; only one reviewer admits that the film is also a metaphysical exploration of the way 'Homo sovieticus' has engaged with the cosmos. However, none of the reviews manage to appreciate the film beyond its contextual references to the UssR and its space program. 
American music and lifestyle, and, of course, something peculiar to Russia - in this case, Yuri Gagarin. It's too bad Mironov has degraded to movies such as this one or Pobeg. Evgenii Tsyganov's role is too simple: there's almost no acting and he is far from his best (as in 'Deti Arbata'). It would be really nice if Russian DVDs had labels such as: 'this movie was made for Westerners' or 'for Moscovites only' :), so I would know what to avoid...

An equally eloquent review on a Russian online film database Kinopoisk.ru ${ }^{26}$ is similarly skeptical:

There isn't much to criticize in this film, nor is there much to praise. It is a background movie, a collage of the aura of a bygone epoch. The atmosphere, everyday life and the way people in the 1950s thought, are presented quite credibly. It reminds me of Kuprin's novels: you open them, read them, and it seems you are breathing the air of those days. A picture comes to life. Tsyganov's performance is beyond all praise, probably one of his best roles. The episode where Horsie meets Gagarin, then a young student, who had not even dreamed about space back then, is a good shot. However, don't set your expectations too high. The film does not evoke strong emotions, doesn't make you gasp by the end. It seems that there wasn't much expected from the film in the first place. However, there is nothing to criticize. A nice, light, hearty movie. Fun to watch once. $^{27}$

Thes reviews as such are not the focus of this article, and were not chosen as representative feedback on the film in question. They are presented as illustrations of the ambiguity of the film's narrative, noted by many other reviewers of various levels of expertise; the selected two reviews succinctly sum up that it might be somewhat unproductive to analyze the film solely through the prism of its narrative or its references to historical and contemporary reality. Indeed,

26 The review was accessed at http://www.kinopoisk.ru/film/103737/, 30 March 2015. It is one of 22 reviews of the film available at the website; 10 reviewers rated the film positively, 10 were neutral, and two rated it negatively. While the vast majority of the reviewers acknowledge that the film is either a reconstruction of the Soviet epoch, an exploration of the self or an homage to the dawn of the space age, one satisfied reviewer states that the film is preoccupied with the conditions and implications of a groundbreaking scientific event - the dawn of the space age.

27 All translations from Russian are the work of the author of the text unless stated otherwise. 
at first glance the spectator is offered a glimpse into the life of two men in the provincial Soviet north, their relations with two women, as well as their involvement in the cosmonaut training program. Space is there, but it seems marginal, lurking in the shadows, easily mistakable for a picturesque excuse for a melodrama. However, it is possible to subvert this reading, by proposing that this film is not concerned with representation or psychology at all. Rather, I will argue that it is obsessed by an idea, which is not directly transferrable to or deducible from a character or a cinematographic technique. ${ }^{28}$

This peculiarity surfaces as soon as one attempts to dissect the film according to established analytical categories, such as character analysis. One of the protagonists, German (a possible allusion to German Titov, the cosmonaut initially intended to become the first man in space, only to be substituted by Yuri Gagarin at the very last moment), is a highly motivated fellow, who is apparently a bit too intelligent for his own good: he is studying English and apparently trying to find a way out of the UsSR, seemingly either via ship or via spaceship. His space enthusiasm is caught on by a more simple-minded creature that goes by the name of Konyok, a cook in a local restaurant - not an antagonist but simply a less intelligent and more gullible figure than German. The two men represent one subject: in the film, they do not really function without one another, and appear static and flat. Together, however, they are the driving mechanism of the film, which may thence be read as a profound and meticulous exploration of subjectivity rather than a shallow melodrama set in the Soviet north before the launch of the Sputnik.

The director employs several different techniques in order to create this double-headed subject, whose heads are facing the obscure goal that can provisionally defined as 'going to outer space', and whose body is torn apart by the differing psychological motives of the two men. Throughout the first half of the film, the camera follows Konyok who appears to be stalking German, an intriguing stranger. Around halfway through the film, the point of view changes, and the camera starts squinting at both characters, examining them from the side, in medium shots. In the final third of the film, the director intentionally, almost loudly, shifts the gaze of the camera by another quarter: a tracking shot, following someone dressed like German, suddenly is followed by a medium close-up that shows us the person en face. And the person we are suddenly faced with is not German, but Konyok, who is merely wearing German's clothes.

28 An extended version of the author's analysis of the films in question (Kosmos kak predchuvstviye and First on the Moon), focusing on the concept of the province and provinciality, is available in a vol. 10, iss. 3 . 
Apart from the gaze of the camera, other circumstances reinforce this split and illogical unity embodied by German and Konyok. For instance, there are curiosities of the fabula, which seem to drive the social-realist canonical logic of irrational connections ${ }^{29}$ to the extreme: Konyok is entirely ignorant about German's provenance, his trade, and the reasons for his interest in foreign languages and his rigorous and regular physical training. Despite all of this, he firmly decides to befriend this stranger and to follow him around everywhere he goes. He does not reconsider this decision despite German's apparent lack of enthusiasm, and despite the fact that German proceeds to coldly seduce his girlfriend. Meanwhile, the camera insists: long shots that show the coast, the bridge, a common meeting place and the forest, where Konyok often falls off his bike with a girl in the back seat - all of this is consistently fuzzy, unclear. Medium shots, on the other hand, are always in motion, they shake, shift, slide. The cinematic subject is caught somewhere between these extremes: it is captured in the medium long shot, not as a stabilization and a clarification of the image, but as a caricature: like the figure of Konyok who, once he puts on his idol's clothing, transforms into a caricature of German. He does not become German, he becomes his inefficient replica.

It can be argued that this split has nothing to do with a single person; rather, it is the split that marks the way the film is driven forward, the way it works; it enacts the film's obsession with the nearing, but faraway, imminent, but incomprehensible advent of the space age. This statement is reinforced by the relationship between the sound and the image. Most of the music in the film is diegetic, which is might be a stylistic allusion to the socialist realist tradition of Soviet cinematography. Most of the music heard in the film comes from radio transmitters on the set; and wherever there is music the source of which cannot be traced as easily, such as the music accompanying the closing credits, it is thematically directly linked to the ideas picked up on by the narrative, such as the Soviet national idea, which seems to provide explanations for inexplicable actions. However, it is not the presence and the function of the music in this particular movie that is striking; what strikes most is its loudness: compared to the dialogue, the music is exceptionally loud and sounds forced into the shots. The dialogue, on the other hand, seems to have been muted intentionally, so that it is unclear and muffled: this stylization, which foregrounds the music, creates a remarkable contrast between the visual and sonic images and the spoken word, between technology and the ambient it intrudes into.

29 Mikhail Epstein, The Paradoxes of Postmodernism and Contemporary Russian Culture (Amherst: Massachussets University Press, 1995), 180-210. 
Layered upon one another, all of these techniques almost seem excessive; yet, there is no real closure, no catharsis; the film does not make much sense if seen through a progressive or a deconstructionist lens, as demonstrated by the reviews quoted at the beginning of our analysis. However, if watched from the standpoint of post-Soviet reflections on the impending space age, the film produces a sense of uncomfortable unity, marked by the gap between the event of the dawn of the space age, and existent explanatory frameworks for it. It manages to construct a subject, which both is and is not human, which seems to be driven somewhere into the darkness, and does not have much of an ear for what might be expected of it on Earth.

\section{Pervye na Lune [First on the Moon]}

Kosmos kak predchuvstviye [Dreaming of Space] is not the only post-Soviet Russian film focusing on the beginning of the space age, which neither denies existent memory narratives nor reaffirms them, creating a fictional world driven by an altogether different logic, and therefore proposing that a new highlight be added to existent narratives on both the history of Soviet spaceflight and the history of the beginning of the space age on a more general level.

Alexey Fedorchenko's mockumentary on the memorialization of the Soviet space programme Pervye na Lune [First on the Moon], which appeared in the cinemas shortly prior to Uchitel's Kosmos kak predchuvstviye [Dreaming of Space], arguably achieves a similar result, employing a different strategy; in fact, this contrived history of the Soviet space program in the 1930s is the only humorous reference to the history of Soviet spaceflight apart from Dmitry Astrakhan's 1994 feature film Chetryortaya Planeta [The Fourth Planet].

In order to provide Pervye na Lune [First on the Moon] with a coherent, lighthearted and suggestive storyline, Fedorchenko resorts chiefly to the strategy of postmodernist deconstructive reconstruction. The film does not mock the Soviet space program as such, but rather memories and myths related to it, produced and reproduced by it. The film, also driven by a similar sort of visually explicit spatial frustration as Kosmos kak predchuvstviye [Dreaming of Space], employs most of its capacities to play around with space and time in order to focus on memory: the memory of the mythical Soviet space program. The spectators are invited to follow researchers who are investigating the unreliable evidence of the existence of the space program in the 1930s in order to track down the details of Ivan Kharlamov's flight to the Moon, which accidentally ended somewhere in Chile. 
The film abuses the authority of archival footage ${ }^{30}$ and neutral narration, as well as construed testimonies of fake witnesses to present a story of what appears to have been the logical step that had to be taken before Yuri Gagarin's first spaceflight in 1957. Many spectators were actually convinced that the director intended to ridicule the history of spaceflight, while some interpreted his intention in the very opposite way; according to certain layman reviews, the film reconstructs the mythology of the history of Soviet achievements in space exploration by adding a supplementary myth. According to an elaborate review on Kinopoisk.ru, the quality of this undertaking, whichever way one interprets it, leaves much to be desired:

... I've wanted to watch this mockumentary for a while. Finally, I managed to find an hour to do this yesterday (luckily, the film is not long). I am sorry I wasted my time on Pervye na Lune [First on the Moon]. I think everything is bad: the idea, the realization, the actors. Ok, so they shot a scene, aged the shots using scratches and blotches. Well, you might as well have done something with the sound, it obviously doesn't correspond to 1930 chronicles. Could they at least have watched something from those times? Or they hoped their memory was good enough? This soundtrack makes one suspicious of every shot, as you no longer believe the fiction or the fake 'interviews' or the 'hidden camera' episodes. Maybe the director should have used more archive materials or watched Kuryokhin's Two Captains 2 - what a great mockumentarist! One to learn from!... Or, you could have tried to find working equipment from those times, tried to film using it, at least to understand what things were supposed to look like. ... Also, they should have read Pelevin's Omon Ra. And maybe done an adaptation of that novel, instead of coming up with their own. I'll give it a slightly higher grade than I normally would have, because my wife fell for it. ... ${ }^{31}$

30 Although seemingly full of archive materials, the film actually does not use more than 10 per cent of authentic archival footage. The rest of the shots were skillfully edited in order to appear old. (Kinopoisk.ru).

The review was accessed at http://www.kinopoisk.ru/film/16099o/, 15 May 2015, and is one of seven reviews on the film available at Kinopoisk.ru. It is an example of the only negative review of the film; the other six reviewers gave it a positive mark. However, all of these seven reviewers share the view that the film is first and foremost a mockumentary, and that it plays with the mythology of Soviet supremacy in outer space. Notably, one reviewer observes that there is a 'mystical' quality to the film, not directly related to its contents or formal qualities as such, but related to the mysticism related to the 
Indeed, the film succeeded in one matter: in creating plenty of confusion. Up until the very end, the film insists on sticking to the form of the documentary, like a persistent historian, digging through the archives and following its object of research regardless of the absurdities and illogical elements that tend to undermine the thesis set out at the beginning. The film manages to create a liminal timespace: ${ }^{32}$ it is not yet in the realm of unbelievable parody and no longer a serious conspiracy theory.

This aspect of the form of the film seems to mirror the irrational, blind persistence that guides all basic research (research for its own sake, the primary aim of which is not applicability, but scientific discovery) and that occurred before the actual beginning of the space age. This blind belief in the necessity to continue working toward success created the conditions, albeit not always the best ones, for people to stick to patterns of behaviour that might, at one point, bear results (although not necessarily): spaceflight. This is a confusing situation: the space age demanded exceptional effort from the people, and, at the same time, there was never any guarantee that, even if achieved, it would have any direct impact on the lives of the people who were workinh toward creating it. The film focuses on this confusion behind the space age, and shows confusion as crucial for the dynamics that brought about its dawn. There is, for instance, a telling sequence where horsemen ride up to the rocket before its launch. It seems that their helmets are pointing to the absurdity of the entire endeavor: why would one invest in the space program at a time when even tanks and cars were still almost the stuff of science-fiction?

Fedorchenko's film starts off with confusion, but offers no way out of it. Such incoherence often characterizes the dynamic of memory narratives, when the latter are dictated by the ideological centre (the metropolis, perceived as a mythical, unattainable centre of progressive thought, planning and lifestyle) and allowed to trickle down to the backward periphery, which always only receives and does not produce progress. ${ }^{33}$ Memory narratives received by the geographical and mythical (backward, faraway) periphery from the ideological and mythical centre are therefore often inconsistent with local

utter unknowability of the cosmos. The film was also reviewed by four IMDB users; three found it to be an amusing and humorous mockumentary, while one stated it is largely incomprehensible to a spectator not familiar with Russian and with the Soviet context of the narrative.

32 Elana Gomel, Postmodern Science-Fiction and Temporal Imagination (London, New York: Continuum, 2009), 10.

33 Cf. Aleida Assman and Linda Shortt, Memory and Political Change (New York: Palgrave MacMillan, 2012), 1-2. 
(provincial or peripheral) memories, which makes these 'instructive' memories, disseminated by the centre, seem superficial, elevated from everyday reality and therefore somewhat fairytale-like.

The film exploits the conventions of the documentary in all of their richness, often providing testimonies of the first Soviet 'cosmopilot', who allegedly flew to the Moon, had an accident in Chile, was admitted to a psychiatric ward in Chita and ended up playing the part of Prince Alexander Nevsky in a circus. His colleagues from the crew of potential cosmopilots, the constructor of the first rocket, one of the cameramen following them around instructed by the secret services, an employee from the psychiatric ward in Chita - all of them prove to be exceptionally enthusiastic respondents to the questions posed by the film crew.

'Everything that happened there got recorded. And if it was recorded, it had to be true, says one of the employees of the archives when introduced to the film crew. Humour here neutralizes the confusion generated by the film, but this at a price: we have to acknowledge that the characters involved in this burlesque are also exceptionally funny. The ex-potential cosmopilot Fattakhov, an orphan, 'raised with love by the Soviet people,' as explained by the omnipresent narrator, and now working as a guard at the zoological museum, spending his days surrounded by huge model insects; the midget who is now a performer at a midget circus, where he is filmed by the crew ... The film deconstructs a myth about a myth. The deconstruction is humorous, but allows for no empathy whatsoever, because all of the characters involved are elevated to the level of a myth and therefore deprived of everything human. The Bakhtinian carnival: the dance of bizarre, eccentric figures who once, a long time ago, participated in a common task, and are now once again brought together in its name, rendered powerful (they speak the truth, as they are witnesses) and powerless (they speak nonsense, because they are caught up in a nonsensical play of empty signifiers, awoken within the mockumentary), appears to be permanent; the carnival is the dynamics of the film. ${ }^{34}$

The visuals are accompanied by Soviet patriotic songs from various periods and Soviet sci-fi 'beeps'; the shots, on the other hand, are another bricolage of sorts: historical data is shown alongside pseudo-documentary montage and shots out of Soviet space films. The only film that is shown to be undeniable fiction, is Kosmicheskiy reys [Cosmic voyage] (dir. Vasily Zhuravlev, 1936), which also examines the possibility of flying to the Moon.

34 Cf. Michael V. Montgomery, Carnivals and Commonplaces: Bakhtin's Chronotope, Cultural Studies, and Film (New York: Peter Lang, 1994). 
The only firm anchor of the film is therefore, ironically, fiction, which does not, in postmodernist terms, replace the reality which is lost and perhaps never was, but appears as an image, pointing to a horrific void behind closed curtains. This is why the affirmatively fictional shots from Kosmicheskiy reys are important: they guarantee that there remains a little something to be trusted: at least some of the fiction is truly fictional. Other shots mainly manoeuvre between fiction and reality, such as the shots of the cameras supervising the cosmopilots. There are even excerpts from advertisements for these cameras in the movie which makes the entire film even more uncanny: everything is shown to be contrived. This is a documentary based on staged, fake evidence.

The film presents the dynamics of the myth of the Soviet space program as confused, contrived, and as a product, greatly conditioned by the tension between the centre and the periphery. It demonstrates that narratives and the imagery of memorialized events may only be perceived as objectively valid, complete accounts of events by subjects who do not fully belong to the centre.

\section{Conclusion}

The two films explored in this chapter highlight a striking ambivalence persistent in memories of the space age and space programs; an enthusiasm allegedly characteristic of the bygone era has been replaced by melancholic disillusionment. This is noted in a large proportion of layman reviews of the two films: they note that the films are reflections on the past, and that this reflection is not positive or assertive, but somewhat contrived: the past is shown in an idealized or a satirized manner; the dawn of the space age is shown as something that was highly mythologized.

On the other hand, cinematic narratives, such as those presented in Kosmos kak predchuvstviye [Dreaming of Space] and Pervye na Lune [First on the Moon] clearly state that there is something more to the space age, something that eludes rationalizations, which reduce the dawn of the space age to the political, economic or technological circumstances in which it occurred. As stated above, only some particularly meticulous reviewers note this quality of the two films. Nevertheless, closer readings of both Kosmos kak predchuvstviye [Dreaming of Space] and Pervye na Lune [First on the Moon] demonstrate that the films resonate greatly with Shukaitis's reflection on outer space as an imaginal machine, a realm offering an opportunity for humanity to radically change its coordinates of social reality instead of reiterating patterns from current affairs on Earth. Kosmos kak predchuvstviye [Dreaming of Space] highlights the ambivalence of a space-bound human subject, its premonition about impending 
change, and its anxiety in view of this change. It contextualizes the dawn of the space age in the USSR within the framework of global politics on the one hand, and with references to individual concerns, which are only partly related to political power constellations, on the other. Pervye na Lune [First on the Moon], although very different from Kosmos kak predchuvstviye [Dreaming of Space] in terms of genre and plot, highlights a very similar tension: the tension between canons of historiographical accounts, the subordination of these accounts to certain ruling political options (the Communist party, in the case of the USSR ), and the inconsistency of both of these sets of guidelines with interpretations given by the individuals involved in the actual events. Furthermore, Pervye na Lune [First on the Moon] ridicules the narrative authority of the format of the documentary, but does not necessarily do so in order to criticize it. Rather, it attracts the spectator's attention to the underlying ideas, i.e. to the idea of the necessity and imminence of the space age, and the radical nature of the transformations it might invoke. Contrasts, such as the contrast between horsemen and a space rocket, illustrate clearly what kind of a leap in thought and technology was required in order to launch the first satellite.

Therefore, both of the films discussed in this chapter are more than reinspections of an important aspect of Soviet (supra)national mythology, the myth of supremacy in the race for space. Both films not only subvert the simple narrative of this myth, which glorifies Soviet scientists, engineers, cosmonauts and politicians, but also provide reflections on a different key dimension of the dawn of the space age; they foreground the fact that it involved various efforts of common, by no means perfect individuals, who relied on the logic of scientific, mathematical language, to launch them into the unknown domain of outer space. Furthermore, the films, particularly Kosmos kak predchuvstviye [Dreaming of Space], emphasize that a transformation, such as the beginning of space exploration, entails a re-examination of the coordinates of our sociocultural and political reality, and an individual's place in it. This dimension of the two films in question is by no means nationally bound, returning our attention to the global significance of humanity's first direct encounters with outer space and ultimately arguing that humanity's space-related achievements are more than mere byproducts of technological progress and politics.

Interestingly enough, as I have attempted to demonstrate in my analysis of the films in question, a lot of analytical attention to the contextual, cultural and national details is required in order to avoid conclusions, which persist in reducing cinematography on the dawn of the space age to reiterations of nationally dominant memory narratives, such as the cited film reviews do. In order to avoid this trap, it seems relevant to return to the formal properties of the cinematic medium, and the formalist aspects of cinematic poetics. 
Supplementing narrative, thematic, character and plot analysis with an analysis focusing on formal features, such as rhythm, sequences of shots and frames, as well as composition, provides a more nuanced insight into cinematic meaning-making, and allows the spectator to enter into dialogue with the cinematic medium as both an agent in memory reception, which presents and argues for its own, original reappropriations of dominant narratives, and an agent of memory narrative production.

\section{Bibliography}

Assmann, Aleida and Linda Shortt. Memory and Political Change. New York: Palgrave MacMillan, 2012.

Carlsten, Jennie M. and Fearghal McGarry, "Introduction". In Film, History and Memory, edited by Jennie M. Carlsten and Fearghal McGarry, 1-19. London: Palgrave Macmillan, 2015.

Dick, Stephen J. "Space, Time and Aliens: The Role of Imagination in Outer Space." In Imagining Outer Space: European Astroculture in the 2oth Century. Edited by Alexander C.T. Geppert, 27-45. Basinstoke, New York: Palgrave MacMillan, 2012.

Epstein, Mikhail. The Paradoxes of Postmodernism and Contemporary Russian Culture. Amherst: Massachussets University Press, 1995.

Erll, Astrid, and Ansgar Nünning. "Concepts and Methods for the Study of Literature and/as Cultural Memory." Literature and Memory. Theoretical Paradigms. Genres. Functions (2006): 11-28.

Fedorchenko, Alexey. Pervye na Lune. Russia: Sverdlovskaya kinostudiya, 2005.

Geppert, Alexander C.T., ed. Imagining Outer Space: European Astroculture in the Twentieth Century. Basingstoke, New York: Palgrave Macmillan, 2012.

Gomel, Elana. Postmodern Science-Fiction and Temporal Imagination. London, New York: Continuum, 2009.

Harrison, Albert A. Spacefaring: The Human Dimension. Berkeley, CA: University of California Press, 2002.

Kinopoisk. Accessed 12 April 2016, http://kinopoisk.ru.

Lathers, Marie. Space Oddities: Women and Outer Space in Popular Culture 1960-20oo. New York: Continuum Books, 2010.

Launius, Roger D. in Howard E. McCurdy. Imagining Space: Achievements, Predictions, Possibilities 1950-2050. San Francisco, CA: Chronicle Books, 2001.

Llinares, Dario. The astronaut: Cultural mythology and idealised masculinity. Cambridge: Cambridge Scholars Publishing, 2011.

Majsova, Natalija. "The Metaphor of the Dawn of the Space Age in Contemporary Social Sciences and Humanities." Družboslovne razprave 31 (2015): 13-30. 
Majsova, Natalija. "The province called earth: the chronotope of the post-Soviet province explored through contemporary Russian cinema on outer space." Studies in Russian and Soviet cinema 10.3 (2016): 223-237.

Maurer, Eva, Julia Richers, Monica Ruthers, and Carmen Scheide, eds. Soviet Space Culture: Cosmic Enthusiasm in Socialist Societies. London: Palgrave MacMillan, 2011.

McCurdy, Howard E. Space and the American Imagination. Baltimore, MA: JHU Press, 1994.

Montgomery, Michael V. Carnivals and Commonplaces: Bakhtin's Chronotope, Cultural Studies, and Film. New York: Peter Lang, 1994.

Nungesser, Verena Susanna. "I Forgot to Remember (to Forget): Personal Memories in Memento (2000) and Eternal Sunshine of the Spotless Mind (2004)". In Media and Cultural Memory, edited by Astrid Erll and Ansgar Nünning, 31-48. Berlin, New York: Walter de Gruyter, 2009.

Poggi, Christine. Inventing futurism: The Art and Politics of Artificial Optimism. Princeton, New Jersey: Princeton University Press, 2009.

Rogatchevski, Andrei. "Space Exploration in Russian and Western Popular Culture: Wishful Thinking, Conspiracy Theories and Other Related Issues." In Soviet Space Culture: Cosmic Enthusiasm in Socialist Societies, edited by Eva Maurer, Julia Richers, Monica Ruthers, Carmen Scheide, 211-265. London: Palgrave Macmillan, 2011.

Schwartz, Matthias. "Die Besiedelung der Zukunft. Zur Neubegründung der sowjetischen Science Fiction nach dem ersten Sputnikflug 1957." In Bluescreen. Visionen, Träume, Albträume und Reflexionen des Phantastischen und Utopischen, edited by Walter Delabar and Frauke Schlieckau, 105-122. Bielefeld: Magazin für Literatur und Politik, Heft 43-44, 2010.

Shukaitis, Stevphen. "Space is the (non)place: Martians, Marxists, and the outer space of the radical imagination." The Sociological Review 57 (2009): 98-113.

Siddiqi, Asif A. The Red Rocket's Glare: Spaceflight and the Soviet Imagination, 1857-1957. Cambridge: Cambridge University Press, 2010.

Suvin, Darko. Russian Science Fiction 1956-1974. Elizabethtown, NY: Dragon Press, 1976. Thompson, Kristin. Breaking the glass armor: neoformalist film analysis. Princeton: Princeton University Press, 1988.

Tvroscosmos. Accessed 9 April 2016, http://tvroscosmos.ru.

Uchitel', Alexey. Kosmos kak predchuvstviye. Russia: TPO Rok, 2005. 